\title{
Cardápios e banquetes na Primeira República:
}

\author{
notas sobre a curadoria de uma exposição
}

\section{Menus and banquets of the First Republic:}

notes on the curatorship of an exhibition

\section{Maria Aparecida de Menezes Borrego' Eliane Morelli Abrahão ${ }^{2}$}

\begin{abstract}
RESUMO: O objetivo deste artigo é discutir o processo de curadoria da exposição "Cardápios e banquetes na Primeira República” (1889-1930), inaugurada em 10 de novembro de 2015, no Museu Republicano "Convenção de Itu" - USP. Partindo das fotografias e cardápios da coleção Washington Luís, as atenções recaíram sobre as dinâmicas de construção de problemáticas e seleção das peças do acervo, o desenvolvimento do projeto expográfico, a realização de atividades correlatas em torno do tema das práticas alimentares entre finais do oitocentos e primeira metade século XX e os desdobramentos da curadoria museológica até os dias de hoje.
\end{abstract}

Palavras-chave: Curadoria; exposição; práticas alimentares; Política-Primeira República (Brasil).

\begin{abstract}
The aim of this article is to discuss the process of curatorship of the exhibition "Menus and banquets in the First Republic" (1889-1930), opened on November 10, 2015, at the Museu Republicano "Convenção de Itu" - USP. Starting from the photographs and menus belonged to Washington Luís collection, attention was paid on the problematic construction and the selection of pieces of the assortment, the exhibition project, the accomplishment of activities around food culture between late nineteenth century and the first years of the twentieth century and the consequences of curatorship to the present day.
\end{abstract}

Keywords: Curatorship; exhibition; food culture; Politics-First Republic (Brazil).

\footnotetext{
1. Historiadora. Docente do Museu Paulista (USP) e supervisora técnico-científica do Museu Republicano "Convenção de Itu" (MP - USP). A autora desenvolveu o artigo no âmbito do Projeto Temático - Fapesp Coletar, identificar, processar, difundir: o ciclo curatorial e a produção do conhecimento, do qual é pesquisadora associada. Contato: maborrego@usp.br.
} 
"O Museu Paulista realiza a pesquisa para a produção de conhecimento científico por meio da curadoria de seus acervos museológico, bibliográfico e arquivístico. A curadoria expressa-se como atividade de pesquisa científica voltada à formação e estudo de coleções; ao estabelecimento de critérios e técnicas de conservação e restauração; ao desenvolvimento de metodologias de ações educativas e - sua face mais visível para a sociedade - à difusão do conhecimento científico por meio de exposições abertas ao público." (Projeto Acadêmico, 2018-2022, Museu Paulista da USP - Museu do Ipiranga e Museu Republicano de Itu, 2018, p. 3)

\section{A curadoria no Museu do Ipiranga e no Museu Republicano de Itu}

O acervo geral do Museu Paulista teve como um de seus núcleos fundadores a coleção de objetos reunida pelo coronel Joaquim Sertório em sua residência, da qual constavam espécimes de história natural e peças de interesse etnográfico e histórico. Em 1890, a coleção foi doada ao Coverno do Estado de São Paulo, ao ser criado o Museu do Estado, logo rebatizado de Museu Paulista, que passou a funcionar oficialmente no bairro do Ipiranga em 1895, daí ser conhecido como Museu do Ipiranga.

Dedicado ao estudo de história natural, mas desde sempre um marco representativo da Independência, a instituição guardava os traços do modelo enciclopédico predominante nos museus oitocentistas, gradualmente caminhando rumo a uma especialização voltada à história nacional, sobretudo a partir da gestão de Afonso de Escragnolle Taunay (1917-1945).

Ele fora nomeado com a incumbência de realizar os preparativos para o centenário da independência do Brasil, a ser comemorado em 1922. Para tão festiva efeméride, tornava-se imperativo inventar a história da nação como um encadeamento lógico, capaz de explicar o Brasil como uma unidade territorial e simbólica, a partir de São Paulo e dos bandeirantes (Brefe, 2005). Para tanto, o passado colonial paulista como alicerce da história nacional foi efusivamente recriado no peristilo, ao redor da escadaria monumental e em várias salas expositivas.

Já em 1923, Taunay seria encarregado pelo presidente do estado de São Paulo, Washington Luís Pereira de Sousa, de também dirigir o Museu Republicano "Convenção de Itu", nascido como extensão do Museu Paulista, e fundado em 18 de abril daquele ano, cinquenta anos após a Convenção de Itu, ocorrida no mesmo dia no sobrado histórico onde está instalado, de propriedade de Carlos Vasconcelos de Almeida Prado (figura 1).

Se 1873 significou as bases para a fundação do Partido Republicano Paulista (PRP), a década de 1920 vivenciaria os sinais de desgaste do partido, após a longa hegemonia no cenário nacional. Em1923, o PRP explorava a comemoração do cinquentenário da Convenção e a criação do Museu Republicano como instrumentos de busca no passado de uma legitimidade histórica para a supremacia do grupo social ligado aos interesses dos grandes cafeicultores de São Paulo (Souza, 2003).

Ficaria a cargo de Taunay supervisionar as adaptações do interior do sobrado ao programa do museu, elaborar a decoração interna e o plano expositivo da instituição calcado na construção tanto da memória republicana paulista como do cenário de uma residência rica da segunda metade do século XIX (Martins, 2012). 


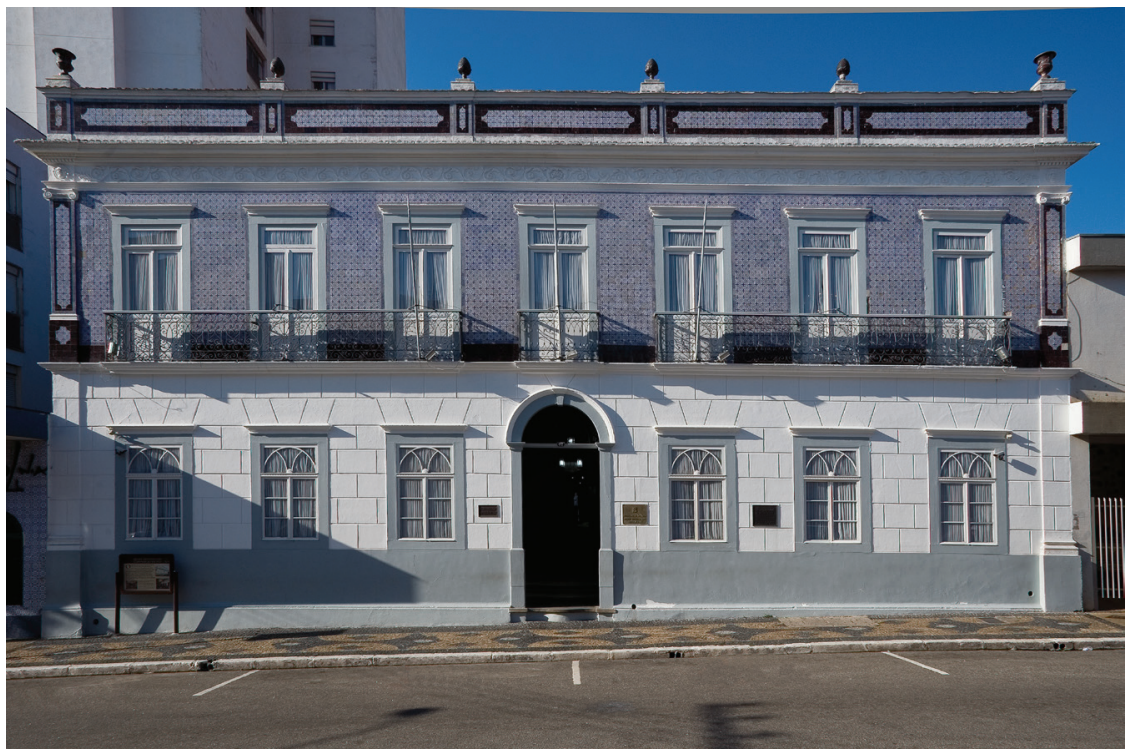

Figura 1: Fachada do Museu Republicano "Convenção de Itu". Fonte: MP - USP"

Entre 1917 e 1989 houve sucessivas transferências de acervos do Museu Paulista para diferentes instituições, sendo a última para o Museu de Arqueologia e Etnologia da USP. A partir deste momento, sob a direção de Ulpiano Bezerra de Meneses (1989-1993), novas diretrizes foram adotadas para o trabalho no Museu do Ipiranga e no Museu Republicano "Convenção de Itu", definitivamente considerados museus especializados em pesquisas no campo da história.

A cultura material foi assumida como área de concentração para as análises desenvolvidas nas três grandes linhas de pesquisa institucionais definidas naquela gestão e ainda hoje norteadoras dos trabalhos no Museu Paulista - Cotidiano e Sociedade, Universo do Trabalho e História do Imaginário.

Nesse novo projeto, a curadoria passou a ser entendida como o conjunto de atividades orgânica e solidariamente desenvolvidas em torno da pesquisa e dos acervos. Tais atividades contemplam o estudo e a documentação das coleções; a formação e a ampliação de acervo; a conservação e a restauração de documentos textuais, iconográficos e tridimensionais; o desenvolvimento de ações educativas; as exposições; os cursos de extensão em suas diferentes modalidades; os seminários; as disciplinas de graduação e de pós-graduação.

\section{Problemática e acervo na montagem da exposição}

Foi a partir de memórias oficiais evocadas pelas fotografias da coleção Washington Luís que iniciamos o processo de curadoria da exposição de longa duração Cardápios e banquetes na Primeira República, inaugurada em 10 de novembro de 2015, no Museu Republicano "Convenção de Itu". Doado à instituição por seu neto, Cesar Luís, em 1995, o conjunto iconográfico corresponde a 4884 imagens e traz informações sobre as visitas oficiais e as obras públicas inauguradas pelo estadista ao longo de sua vida política'. 
Ao folhear os álbuns fotográficos buscávamos apreender, a um só tempo, o Brasil que as lentes dos fotógrafos intencionalmente captavam e as formas pelas quais o regime republicano ia se impondo nas mais recônditas localidades do território nacional nas primeiras décadas do século XX.

Nesse conjunto, encontramos várias imagens do político em banquetes, o que nos levou a refletir sobre a importância desses eventos sociais públicos na República recém-criada e a conjecturar sobre o papel dos jantares e almoços para selar alianças políticas, firmar negócios, homenagear figuras ilustres - em geral ao som de orquestras - e exercitar a eloquência e a retórica por meio de discursos.

A esses documentos se somou a coleção de cardápios também reunida por Washington Luís que pertence ao acervo, formada por 56 menus completos - com informações sobre os alimentos, as bebidas e, em alguns casos, o programa musical do evento - e oito convites para reuniões sem as respectivas listas de iguarias ${ }^{2}$.

O material, até então inédito, começou a ser visto com vagar. A análise das características físicas e dos conteúdos dos menus nos levou à nova problematização sobre sua presença nesses eventos. Para além da função primeira para que foram confeccionados - servir como suporte para apresentação dos pratos de uma refeição -, os cardápios passaram a ser analisados em sua materialidade - formato, textura do papel, características gráficas, idioma adotado. Para compreensão desse gênero documental, portanto, conteúdo e forma foram conjugados a valores estético e gráfico.

Ademais, a informação sobre os ingredientes e as bebidas privilegiados em determinadas ocasiões acabou por sugerir as formas requintadas de preparo dos alimentos, os utensílios a serem utilizados pelos convidados, o tipo de serviço adotado, a sequência dos pratos e a preocupação que se tinha ao atribuir nomes às iguarias, descortinando uma incipiente brasilidade culinária.

Para bem compreender o léxico dos cardápios e a sua própria difusão no Brasil daquele período, em particular, e no mundo ocidental, em geral, a literatura consultada nos alertou que era fundamental termos em mente que as transformações da arte de bem comer ocorreram em diferentes épocas, traduzindo preferências e variações dos paladares (Flandrin, 2002, pp. 141-164). Como decorrência dessas modificações alimentares ocorreu a paulatina substituição do serviço denominado à la française pelo à la russe.

As diferenças entre a estrutura dessas refeições estavam na concepção dos jantares. $\mathrm{O}$ esquema à francesa tinha uma ementa com diferentes serviços. As iguarias eram trazidas à mesa de uma só vez e, ao término de cada coberta, esta era substituída pela seguinte, e assim sucessivamente. Havia entre três e cinco serviços, número este que variava de acordo com a quantidade de convidados e estava intimamente relacionado à suntuosidade da refeição. Cada serviço compreendia numerosos pratos frios e quentes, doces e salgados, que eram distribuídos 
pela mesa obedecendo a uma ordem precisa e determinada (Laurioux, 1989, pp. 91-92). Enquanto no service à la russe, alterou-se a quantidade de iguarias e a forma de apresentá-la aos convivas.

Assistiu-se a um desfile de louça miúda, durante o qual os molhos, extratos e sucos substanciosos, consommés e sopas finas, caldos e gelatinas isentavam os comensais da obrigação trivial de morder, trincar e mastigar - grandes peças de assados da mesa pantagruélica -, favorecendo colóquios delicados e sutis conversações, de acordo com Piero Camporesi (1996, pp. 12-13). Surgia um novo tipo de conviva: um indivíduo que comia com elegância e discrição pouca comida servida em várias etapas. Essas mudanças comportamentais nas regras e nos códigos de convívio social assim como na crescente valorização do manger - como parte da nova mise-en-scène essencial ao status da burguesia europeia, principalmente francesa - consolidaram o jantar festivo como um dos grandes símbolos de prestígio social do século XIX.

No serviço à la russe numerosos criados eram indispensáveis do primeiro ao último minuto da refeição visto que os pratos eram trazidos à mesa já prontos para o consumo e eram colocados à frente de cada convidado sucessivamente, até a sobremesa. A ordem das iguarias era definida pelo chef-entrada fria, sopa, peixe, carne, sobremesa. Os vinhos e licores eram selecionados previamente para harmonizar com as várias cobertas a serem servidas durante o festim.

Com a adoção deste serviço, os cardápios ganharam destaque. Inicialmente, consistiam em uma lista de pratos escrita em folhas soltas, distribuída aos convidados por ocasião do jantar. Posteriormente, tornaram-se fundamentais ao funcionamento dos restaurantes e casas de pasto, espaços públicos que serviam refeições. Manuscritos ou impressos, em cartão, papel ou tecido, os menus foram próprios do século XIX e se inscreveram num contexto de valorização do requinte e das boas maneiras (Braga, 2006, pp. 19-25). Como as listas documentavam o que os comensais degustaram em diferentes oportunidades, não era incomum à época que os convivas os guardassem, quer pela beleza do material, que como recordação desses momentos de convivência social.

No Brasil, essa prática de colecionismo não foi diferente como testemunham os conjuntos de menus de D. Pedro II, Rui Barbosa, Olavo Bilac, Francisco Pereira Passos, Thomaz Alves Filho, Washington Luís, Sinézio Rangel Pestana, entre outros. Boa parte das listas chegava ao país préimpressa, com as imagens decorativas gravadas por casas francesas, influenciando as tipografias que se instalariam no país em meados do século XIX, entre elas a Jules Martin, Laemmert e G. Leuzinger \& Filhos, de acordo com o estudo de Francisco Lellis e André Boccato (2013, pp. 38-42).

Era usual confeccionar as minutas em francês, geralmente feitas em papéis de alta gramatura, lembrando a textura do papel-cartão. Os motivos decorativos às vezes traziam imagens de alimentos ou fotografias, como complemento ao título eà lista de pratos. Outras particularidades como datas, desenhos feitos à mão, nome do anfitrião ou assinaturas dos presentes à recepção são encontrados nesses documentos (figuras 2, 3, 4, 5). 

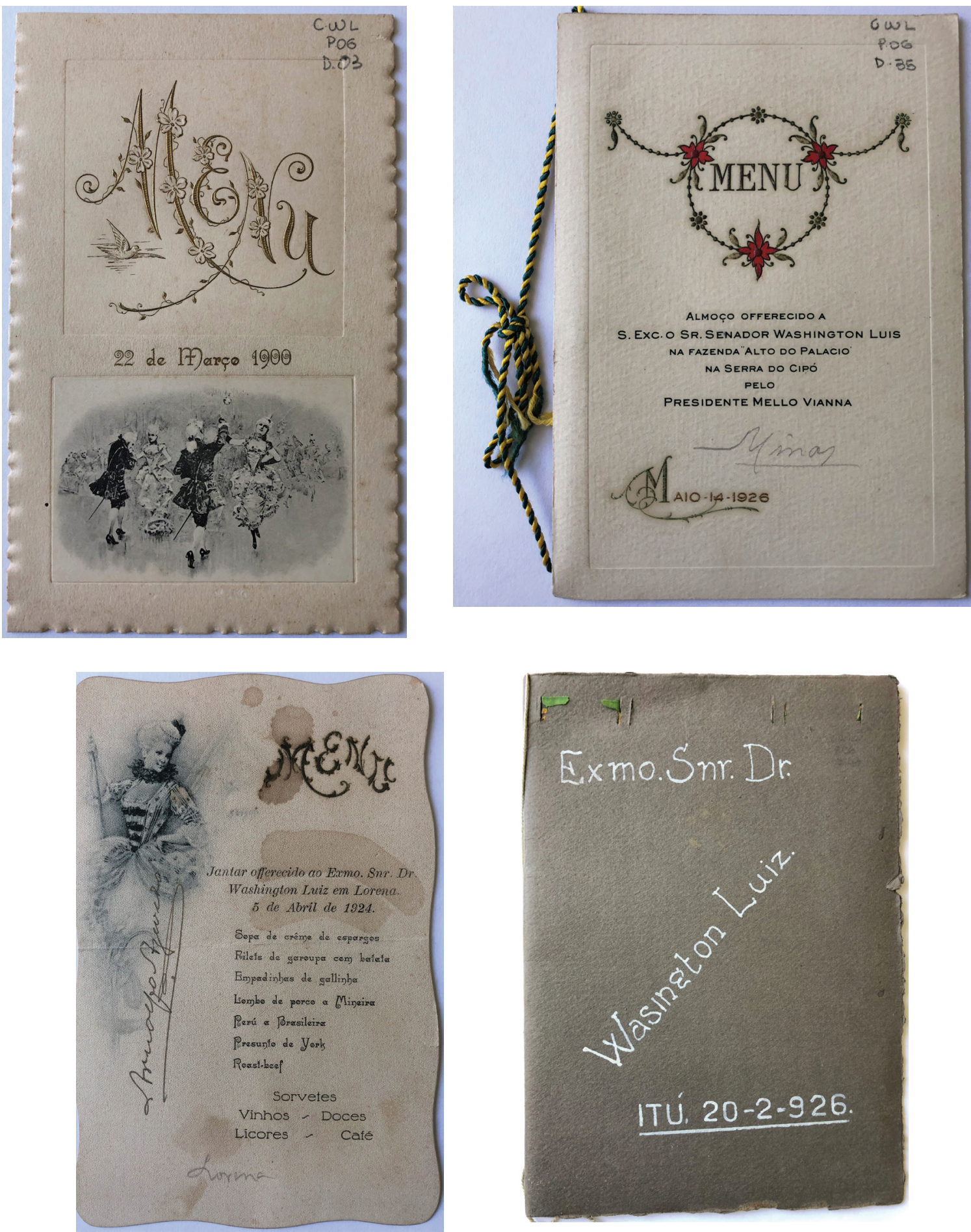

Figuras 2, 3, 4, 5: Ilustrações eram comuns nos cardápios, impressas ou feitas à mão. Fonte: Coleção Washington Luís - Museu Republicano Convenção de Itu (MRCI) - MP - USP.

Os cardápios serviam a finalidades diversificadas e estavam ligados a uma sociabilidade praticada em espaços públicos, como restaurantes, hotéis, cassinos ou clubes existentes na cidade. Quanto aos tipos de reuniões, representadas na Coleção Washington Luís, estão os almoços, jantares e banquetes (figuras $6,7,8,9$ ). 

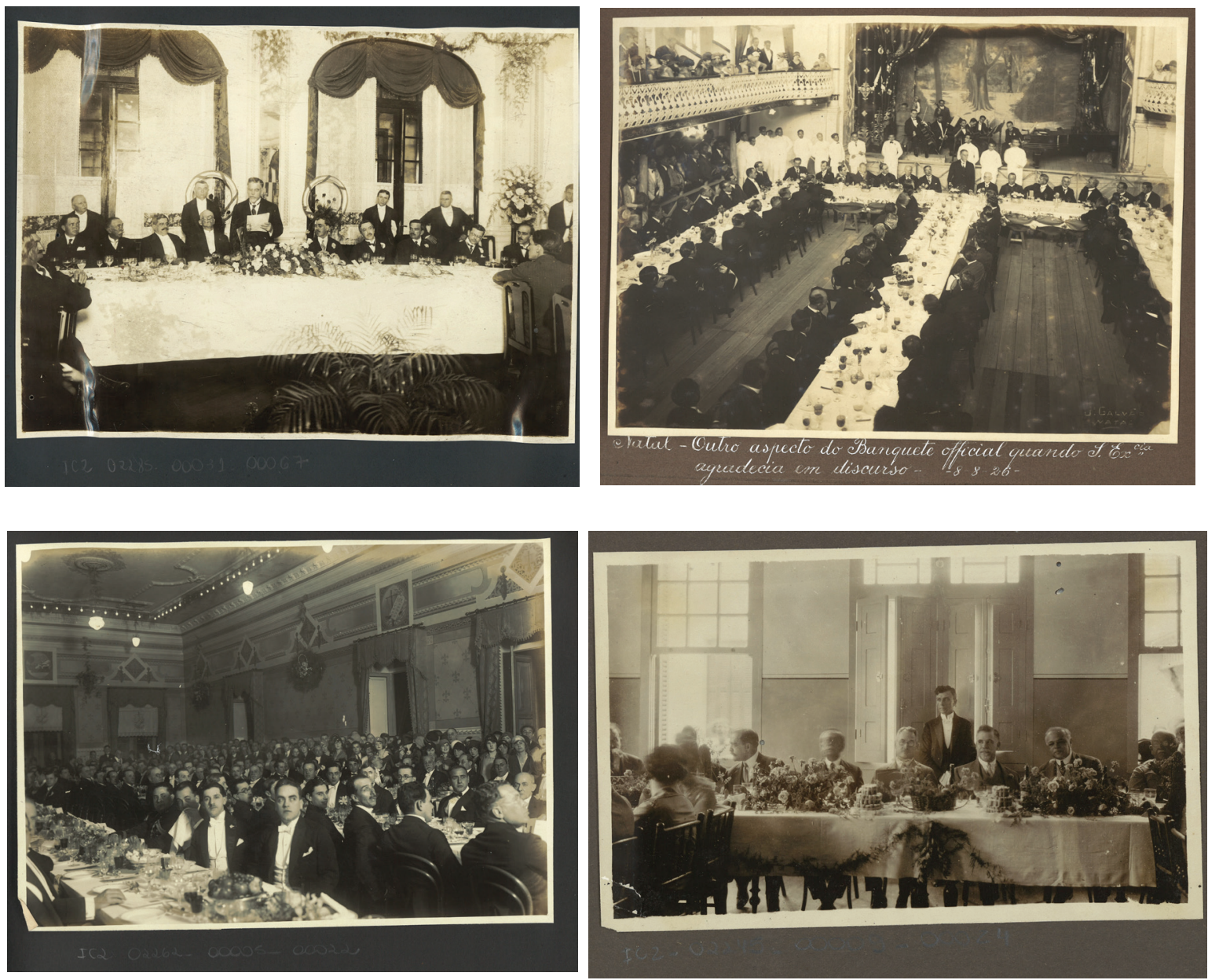

Figuras 6, 7, 8, 9: No sentido horário, banquetes oferecidos a Washington Luís nas cidades de Jacareí, Natal, Itu e Juiz de Fora. Fonte: Coleção Washington Luís - MRCI - MP - USP.

O estilo das refeições variava conforme a ocasião, indo de um lunch de cunho comemorativo pelos pleitos conquistados, até almoços e jantares para comemoração de inaugurações de estradas de ferro e de rodagem, fábricas, escolas, asilos, entre outros, que culminavam geralmente com os discursos do anfitrião e do homenageado, como observamos nas duas primeiras imagens (figuras 6 e 7). Sobre este aspecto, comentava Olavo Bilac:

É absurdo confundir a oratória [...] da praça pública, e das tribunas populares, eclesiásticas, forenses e acadêmicas, onde o orador fala com o estômago vazio, e apenas tendo o direito a um copo d'água para a irrigação periódica da garganta - com a oratória dos banquetes, dos piqueniques, e das ceias, onde o orador fala com o estômago abarrotado, e onde a imagens saltam com a farofa, do bojo dos perus assados, e os tropos saltam, com os vapores alcoólicos, das taças de champagne, dos copos de cerveja e dos cálices de vinho do Porto. (Olavo Bilac33, apud Garcia, 2011, p. 86) 
Quanto ao idioma adotado nos cardápios da coleção, atestamos que $50 \%$ dos menus estão em língua francesa e os outros 50\% em português (figuras 10, 11). Para além do idioma, a influência dos modelos estrangeiros estava inserida nos padrões comportamentais da sociedade paulista, com evidentes repercussões no convívio social, especialmente nas ocasiões festivas. Trata-se de informações implícitas ao documento e que descortinam as práticas sociais de uma época na qual os valores culturais vivenciados pelas elites eram fortemente influenciados pelo cosmopolitismo francês - a Belle époque brasileira - cuja duração abarcou, grosso modo, os anos finais do Império até princípios da década de 1920.
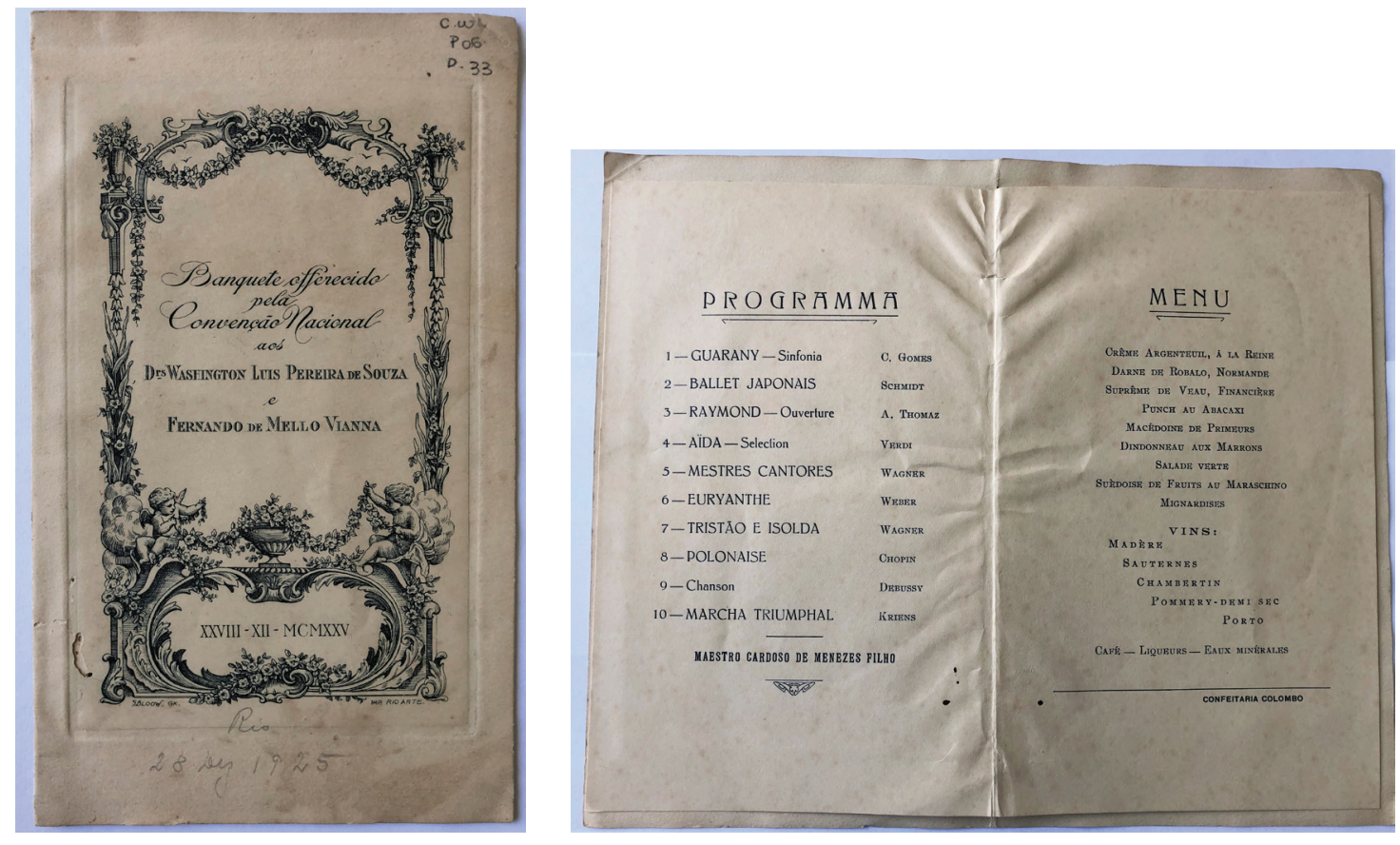

Figuras 10, 11: Banquete oferecido pela Convenção Nacional ao Dr. Washington Luís Pereira da Souza e Fernando de Mello Viana, Rio de Janeiro, 28 dez. 1925. Fonte: Coleção Washington Luís - MRCl - MP - USP.

Por outro lado, em contraponto aos estrangeirismos, os movimentos regionalista e modernista propuseram estabelecer uma identidade local e, entre os diversos aspectos apontados pelos intelectuais, a comida tipicamente brasileira seria um deles, tal como indica alguns dos cardápios da coleção apresentada nesta exposição. Pratos como Tartaruga ensopada com batatas, Camarão com coco à nordestina, Frango de molho pardo, Carne do sertão com farofa à sertaneja e Assado de porcoà paulistana sugerem a identidade dos ingredientes com al gumas regiõese, consequentemente, com o Brasil. O regional aparecia, assim, contido no nacional.

Dada a dimensão do território brasileiro e a riqueza das culturas locais, o projeto de uma única cozinha é utópico. No entanto, os cardápios são reveladores da regionalidade dos alimentos, como verificado, por exemplo, nos almoços oferecidos a Rui Barbosa e a Washington Luís pela municipalidade de Jacareí, região do Vale do Paraíba, São Paulo. Rui Barbosa, em plena campanha à Presidência do Brasil (1909), pôde degustar "Canja, Viradinho à Paulista, Lombo de porco com 
batatinhas, Frango com champignon, Rosbeafao natural, Arroz de forno, Peru à brasileira e Fiambre"4.

Já Washington Luís, então Presidente do Estado de São Paulo (1923), no almoço que lhe fora oferecido na mesma cidade anos depois, teve a oportunidade de saborear outros pratos (figuras 12, 13), como se vê pelo cardápio a seguir:
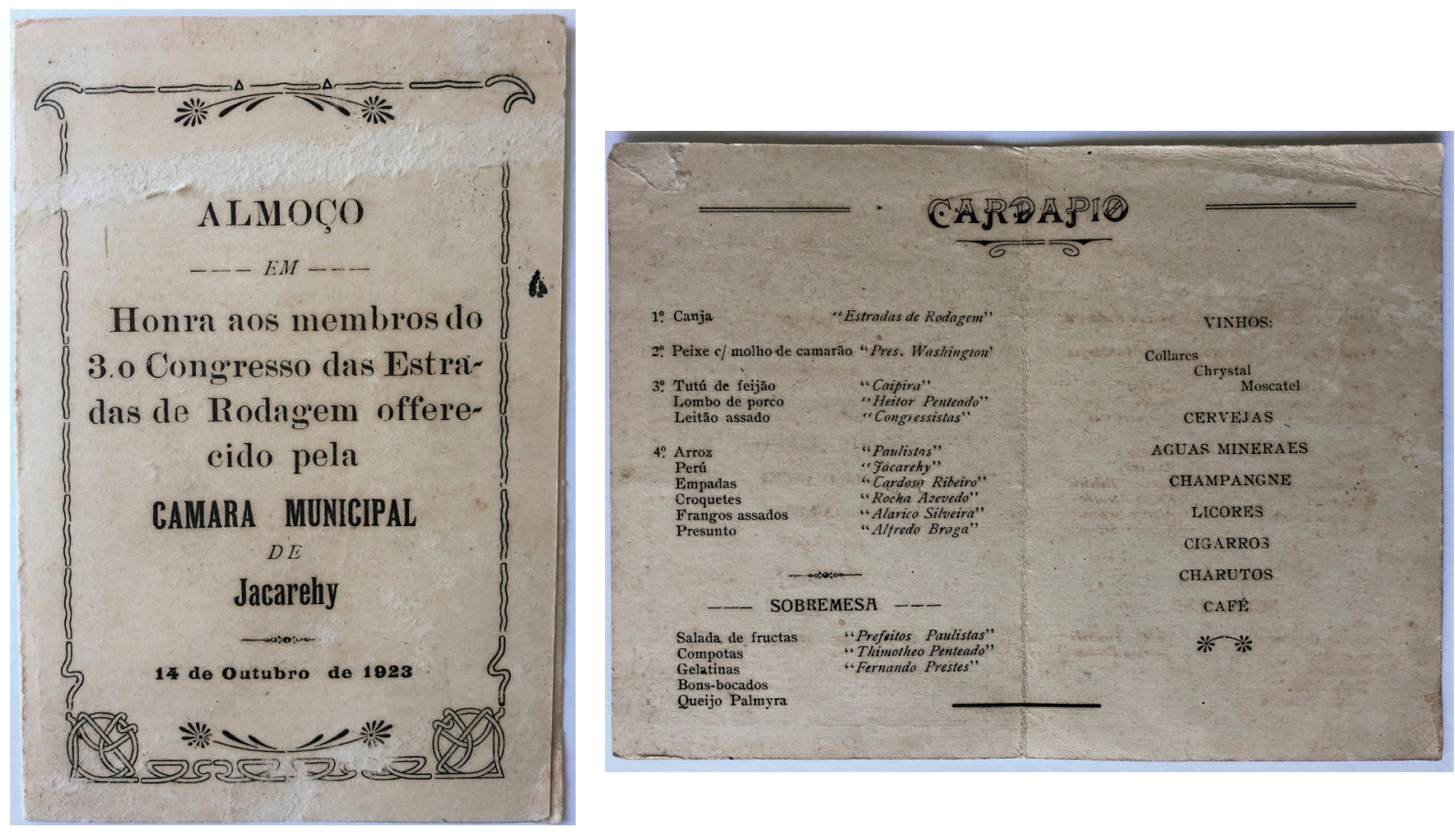

Figuras 12, 13: "Almoço em honra aos membros do $3^{\circ}$ Congresso de Estradas de Rodagem oferecido pela Camara Municipal de Jacarehy”, Jacareí, 14 out. 1923. Fonte: Coleção Washington Luís - MRCl - MP - USP.

Percebe-se no primeiro cardápio uma mescla total dos sabores "locais" - como o virado de feijão, a carne de porco e de frango - com ingredientes e pratos da culinária internacional-cogumelos, rosbeafe fiambre-, provavelmente para dar um toque de requinte ao cardápio. Enquanto no segundo almoço as iguarias típicas receberam nomes de personalidades e de realizações políticas paulistas.

De toda forma, a partir do levantamento realizado junto aos pratos dos menus e às pesquisas empreendidas, identificamos que o Peru à brasileira era o momento alto do jantar. Outra peculiaridade refere-se à nomenclatura dada ao prato em questão, pois encontramos desde Dindin imperiale, Dinde a la Republique e Dinde à brésillienne. Por sua reincidência nos cardápios daqueles jantares, o Peru à brasileira pode ser considerado o retrato gastronômico de uma época, assentado na premissa de que os gostos predominantes na alimentação estão vinculados ao cotidiano de uma determinada sociedade, sendo por isso capazes de espelhar as mudanças socioculturais e políticas pelas quais passava o Brasil.

A leitura da bibliografia indicou que não só nos eventos públicos os banquetes tiveram proeminência, mas também nas reuniões sociais oferecidas pelas elites no ambiente doméstico. As cerimônias dealmoço ejantar muitose prestavamaoestabelecimento ou reforço de laços políticos 
e econômicos, legitimando os valores de classe e, outra face da mesma moeda, "discriminando aqueles que não tinham o pleno domínio de seus códigos de etiqueta" (Carvalho, 2008, p. 189).

Nesses momentos de congraçamento familiare social, os menus eram pensados e preparados com o objetivo específico de inteirar os comensais sobre o que lhes seria servido durante o jantar, tanto que Vera Cleser recomendava - entre outros detalhes sobre a arrumação e a decoração da mesa de jantar - que no lugar previamente designado a cada convidado se deveria colocar sobre o prato, ou próximo a ele, um exemplar do cardápio com a lista dos comes e bebes a serem oferecidos durante a refeição. E finalizava: "Estes cartões vendem-se em todas as livrarias: escreve-se nelle o nome de cada iguaria na ordem dos serviços" (Cleser, 1906, p. 205).

A mise-en-scène em torno dos jantares, ou seja, os cuidados com a escolha da louça, das toalhas, dos ornamentos e com os alimentos pode ser apreendida pelas notícias propaladas nos periódicos. Discorria-se sobre a decoração do ambiente, a disposição da mesa e o serviço do banquete, inclusive com descrições das iguarias servidas na ocasião.

Os ambientes dedicados à sociabilidade nas residências das famílias da elite cafeicultora estavam materialmente equipados com o que havia de mais moderno, dando respaldo aos rituais e protocolos próprios do ato de alimentar-se enfatizados nos manuais de etiqueta. Orientações sobre como estender a toalha, observar a distância correta de um prato a outro, a disposição dos talheres e do guardanapo perpassando também o número de copos, determinados pelas qualidades de bebidas que seriam ofertadas aos comensais, foram destacados na publicação O livro das noivas, de Julia Lopes de Almeida (1929, pp. 30-31).

A atuação das mulheres era crucial para assegurar os altos padrões estéticos das moradias e delas dependia em grande parte o prestígio de seus maridos, já que o espaço doméstico tornara-se vitrine, não apenas da dona da casa, mas de toda a família, como ressalta a literatura sobre etiqueta e comportamento (Carvalho, 2008, pp. 275-276).

Com base no arrolamento dos bens presentes em inventários post mortem, Eliane Morelli Abrahão (2010) inferiu que as mulheres da elite campineira deixaram sinais de que apreenderam os preceitos e modelos propagados nos tratados de civilidade, assim denominados, ou seja, as regras do "saber viver". Isso pode explicar porque suas casas estavam fartamente aparelhadas com objetos de decoração, mobiliário e utensílios de luxo como pratos, travessas, jarras, copos e talheres, indicando plenas condições de receber de forma elegante seus convidados por ocasião dos jantares cerimoniosos, bailes e chás da tarde.

Os inventários de bens ainda atestam que a sala de jantar despontou como lugar ideal para a ostentação de riquezas e poder que dava suporte à manipulação dos quadros de ordenamento e reordenamento social das famílias. Segundo análises de Pilla, nos manuais de etiqueta dos inícios do séculoXX, "as qualidades em receber, oferecer e partilhar os alimentos, consistem muito mais em qualidade de esmero, cuidado, do que no luxo das iguarias" (Pilla, 2005, p. 64). Vera Cleser também destacou esse aspecto em seu manual de boas maneiras, associando o caráter de uma dona de casa com o arranjo da mobília, a escolha dos quadros e a sua disposição nas paredes (1903, p. 128). 
Nos jantares cerimoniosos as cristaleiras, os aparadores do tipo guarda-louça ou étagère eram móveis obrigatórios nas salas de jantar, além da mesa elástica com suas respectivas cadeiras. Nos jantares e banquetes esta mesa deveria estar minuciosamente arrumada com os cristais, as pratarias e a requintada porcelana inglesa ou francesa, que se tornaram um dos mais importantes sinais de opulência e sofisticação.

Os pratos de formatos diversos, travessas, sopeiras, molheiras, cremeiras e os serviços de chá e café recebiam monogramas do proprietário ou brasões quando se tratava dos senhores nobilitados pelo Imperador (figuras 14, 15, 16)5. A decoração incluía ainda quadros, pinturas, vasos e castiçais. Mangas de vidro ou cristal cercavam e protegiam as chamas das velas suportadas por castiçais de prata.
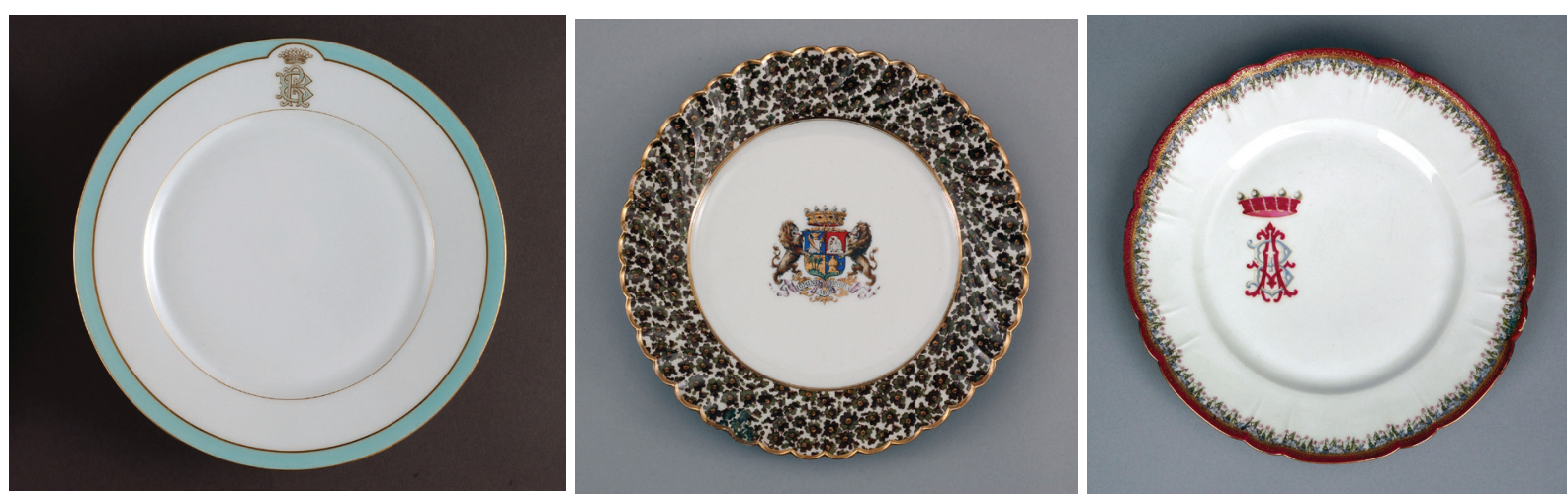

Figuras 14, 15, 16: Pratos das coleções Visconde do Rio Branco, Barão de Miranda e Barão de Anajás, respectivamente. Fonte: MP - USP.

Enquanto os caros serviços de mesa importados eram adquiridos pelas famílias abastadas, as camadas médias e populares consumiam louças mais baratas, mas também decoradas. Ao longo do século XX, as fábricas de porcelana estabelecidas no Brasil produziram serviços de café, chá e jantar para diversos tipos de público. Nesse contexto, o grande desenvolvimento da chamada indústria de louça paulista pode ser encarado como resposta à demanda de uma parcela mais alargada da população que não participava dos banquetes em eventos públicos, nem frequentava as residências das elites. Por outro lado, tais fábricas foram também indutoras do gosto por meio das campanhas publicitárias que patrocinavam o consumo de artefatos a serem usados nas refeições.

Assiste-se, portanto, no caso do Império e nas décadas iniciais da República, à adoção de rituais de alimentação regulados por horários e por hábitos, senão refinados, educados à mesa e em vários segmentos sociais, sobretudo nos espaços urbanos.

Como comunicar todas essas questões ao público que frequenta o Museu Republicano por meio de uma exposição foi nosso desafio ${ }^{6}$. Segundo Ulpiano Bezerra de Meneses (1994), para a 
exposição museológica ser considerada como forma de produção do conhecimento histórico, três aspectos devem ser levados em conta pelos curadores de museus históricos: partir da problematização de aspectos das dinâmicas sociais em determinados contextos; conceber o objeto do acervo como documento histórico; e capacitar o público para dominar a convenção visual que organiza a exposição.

Foi o que buscamos seguir na concepção da exposição Cardápios e banquetes na Primeira República. O primeiro passo foi dividi-la em dois momentos de acordo com a realização dos banquetes nos espaços público ou doméstico. A separar os dois ambientes, um grande banner de tecido com imagens de Washington Luís discursando em eventos sociais?

Na primeira parte da mostra, os almoços e jantares festivos ocorridos em restaurantes, hotéis, cassinos ou clubes, com participação de políticos e das elites locais e regionais, foram apresentados ao público por meio de três tipologias do acervo do Museu Republicano de Itu: bustos, pinturas e menus ${ }^{8}$.

Dispostos em forma circular, foram colocados os bustos em bronze de Bernardino de Campos, Manoel Ferraz de Campos Salles, Júlio Prestes e Prudente de Moraes, o primeiro presidente civil do Brasil, nascido em Itu. Nesse mesmo espaço, Prudente de Moraes seria novamente representado de corpo inteiro na pintura de Almeida Júnior, o qual também participa da exposição e do "banquete" por meio de seu autorretrato. A completar o grupo, como personagem-chave, o próprio Washington Luís Pereira de Sousa em tela, pelo pincel de Oscar Pereira da Silva (figuras 17, 18).

Em duas vitrines, foi exibida uma amostra da coleção Washington Luís com características diversificadas de cardápios para que o público pudesse conhecer a multiplicidade de formatos, matérias-primas, elementos gráficos de que eram feitos os originais, além dos pratos e bebidas servidos em cada ocasião. Para que se tivesse conhecimento do conjunto completo, os menus foram disponibilizados em forma digital num monitor colocado acima das vitrines que os apresentava individualmente e em sequência, de forma ininterrupta.
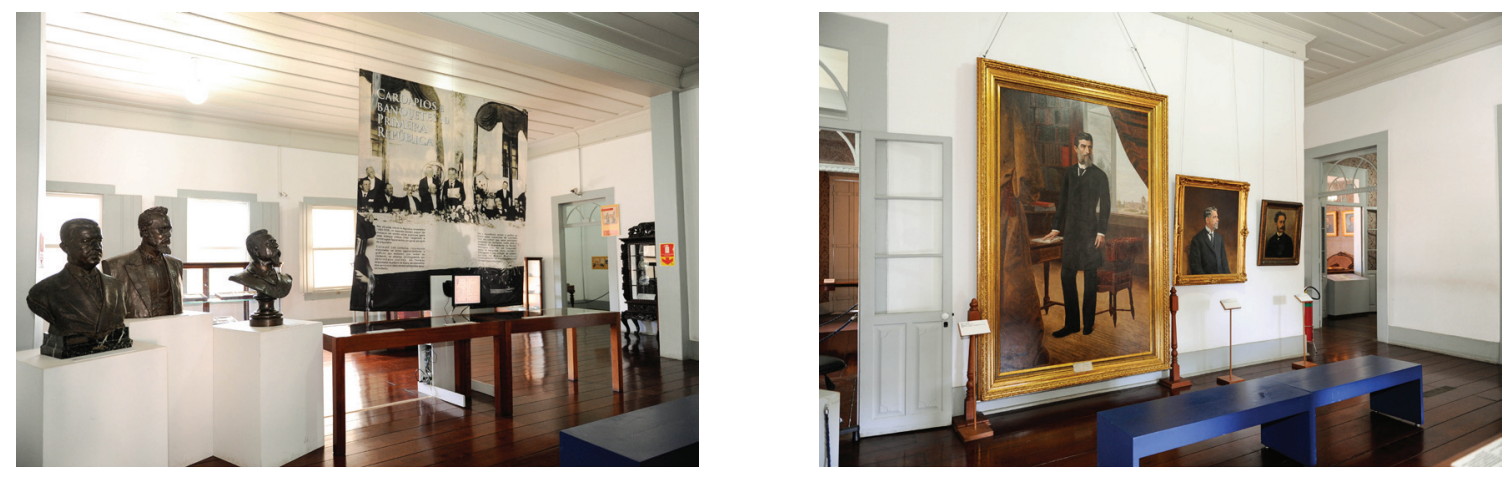

Figuras 17, 18: Vista parcial da exposição no Museu Republicano de Itu. Fotografias de José Rosael.

$7 \quad$ O projeto museográfico foi desenvolvido por Ricardo Bogus e Cláudio Rother a partir da discussão de questões com a curadora da exposição, Maria Aparecida de Menezes Borrego.

8 A montagem da exposição foi feita por Marcos Steiner, Paulo Zacharias, Cilas de Souza e contou com os serviços de manutenção de Benedito Aparecido e Cristiane Monteiro. Paulo Roberto dos Santos e Flávio Xavier dos Santos foram os responsáveis pelas compras e pela infraestrutura necessária para a realização de todas as atividades curatoriais. 
Já para o ambiente doméstico, o processo de concepção da exposição tomou caminho diferente, ou seja, ao invés de partirmos do acervo para a formulação de problematizações, foram as questões advindas das leituras que nos moveram a selecionar outras peças do acervo para discutirmos o papel dos jantares e do espaço privado como sinal de distinção naquele contexto histórico do início do século XX (figura 19).

A montagem da exposição oscilou, assim, o tempo todo entre problemática e acervo, que se reforçaram mutuamente na escolha de aspectos a serem abordados e peças a serem mobilizadas, vivenciando a prática da curadoria museológica tal como colocada por Meneses:

Coleção ou problemas? É, antes, de uma problemática que se deve partir. Mas, já que se trata de museu, de uma problemática que possa ser montada (ou melhor montada) com objetos materiais. Portanto, instaura-se uma dialética sem exclusão, em que a problemática define um horizonte de documentação potencial desejável e em que, por sua vez, categorias documentais permitem delinear territórios de problemas a serem formulados e explorados. (Meneses, 1994, p. 17)

Como as peças do Museu Republicano não eram suficientes para comunicarmos as problemáticas construídas, partimos para uma coleta ativa de artefatos para o preenchimento de lacunas, ainda que tal coleta tenha se restringido a peças ligadas ao processamento de alimentação pertencentes ao Museu do Ipiranga. Decorrentes desse levantamento, foram selecionados conjuntos de chá e café e serviços de jantar importados e nacionais, talheres, copos, descansos de mesas e paliteiros, que foram transportados para Itu a fim de comporem a exposição. Cabe mencionar que participaram desta seleção profissionais dos serviços de Documentação, Objetos, Biblioteca, Conservação e Educativo do Museu Republicano, que desde o início estiveram envolvidos no processo curatorial.

Dentre as coleções de porcelana francesa, elegemos parte dos serviços de jantar do Visconde de Indaiatuba, fabricados por M. Redon Delinières e Haviland - Ateliê Mansard, de Limoges, e da Segunda Baronesa de Jundiaí, produzidos pela Casa Gauvain, também em Limoges (figura 19). Os titulados do Império foram escolhidos por sua atuação na cafeicultura em região próxima a Itu. Joaquim Bonifácio do Amaral (São Carlos, 1815-Campinas, 1884), por exemplo, foi agraciado com o título de Barão de Indaiatuba em 1876 e de Visconde de Indaiatuba em 1879. Já Anna Joaquina do Prado Fonseca (Jundiaí, 1821-1906) era filha do sargento-mor Antonio Queiróz Telles, Barão de Jundiaí, e de sua mulher, D. Anna de Morais Jordão, $1^{\mathrm{a}}$ Baronesa de Jundiaí, sua sobrinha. Foi agraciada com o título de $2^{\mathrm{a}}$ baronesa em 7 de maio de 1887.

Numa das vitrines estão expostas peças da Coleção Olga de Souza Queiroz. O serviço de porcelana francesa produzido pela Casa Gauvain, na Manufatura Pouyat, foi encomendado por Augusto de Souza Queiróz, fazendeiro de café e político paulista nascido no século XIX. Seu monograma -ASQ - está gravado em cada uma das 83 peças do conjunto. A riqueza de seu serviço se mede também pela grande quantidade de tipos de objetos: pratos rasos para o alimento principal, para o couvert, para a sobremesa, pratos fundos para as sopas, prato para bolo, bandeja, queijeira, molheira, azeitoneira, travessas diversas, sopeiras, fruteiras, cremeiras, além de xícaras de chá e café (figura 20). 

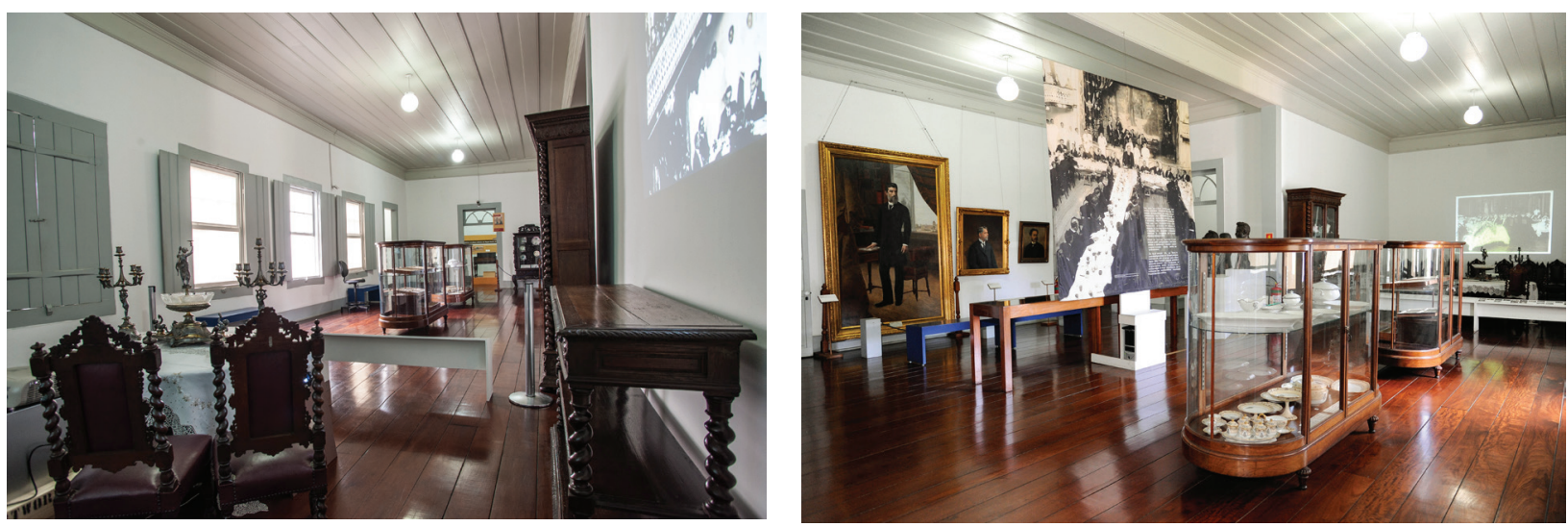

Figuras 19, 20: Vista parcial da exposição no Museu Republicano de Itu. Fotografias de José Rosael.

Também muito nos beneficiamos das peças que haviam sido adquiridas para integrarem a exposição Morar Paulistano, sob curadoria de Vânia Carneiro de Carvalho (2011), cuja inauguração foi postergada em razão do fechamento do Museu do Ipiranga para reforma, em 2013. Os talheres usados na exposição, por exemplo, fazem parte do faqueiro alemão com 203 peças Art Krup Berndorf, comprado como objeto cenográfico.

A expansão dos rituais de alimentação entre segmentos sociais alheios e alijados do círculo restrito das elites foi apresentada por meio de artefatos produzidos pelas fábricas de louça paulista na década de 1930, como um descanso de mesa, fabricado pela Manetti, Pedotti \& Companhia Ltda, instalada em Mauá, São Paulo; uma bandeja para bolo e um prato de sobremesa, manufaturados na Fábrica de Louças Cláudia, das Indústrias Reunidas Francisco Matarazzo, em São Caetano do Sul; um prato de sobremesa, da Fábrica de Louças Adelina, da Barros Loureiro \& Filhos (figura 21).

Todas as peças foram feitas em faiança "pó de pedra", produzida pela moagem de argila, caulim, quartzo e feldspato, de maneira a se obter uma pasta clara, a qual é submetida ao torno ou à fundição e, posteriormente, às queimas. Embora o processo de fabricação de faianças e porcelanas seja similar, no caso da porcelana, as temperaturas exigidas são superiores, a massa homogênea não apresenta porosidade e a fusão com o esmalte é perfeita, o que garante às peças impermeabilidade, translucidez e maior resistência mecânica (Pereira, 2010).

Já a permanência de hábitos alimentares não condizentes com os gestos civilizados propalados pelos manuais de etiqueta e que atingiam todas as camadas sociais foi mostrada por meio dos paliteiros de porcelana fabricados no Brasil, na Alemanha e em Portugal (figura 22). Mesmo em face das recomendações das boas maneiras, as indústrias estrangeira e nacional de louças produziram peças delicadas e ornamentadas, indicando a persistência do hábito de palitar os dentes à mesa. Banidos aos poucos da sociedade ocidental, os paliteiros foram sendo descartados das mesas elegantes até desaparecerem de eventos sociais e restaurantes, como testemunhamos hoje em dia. 

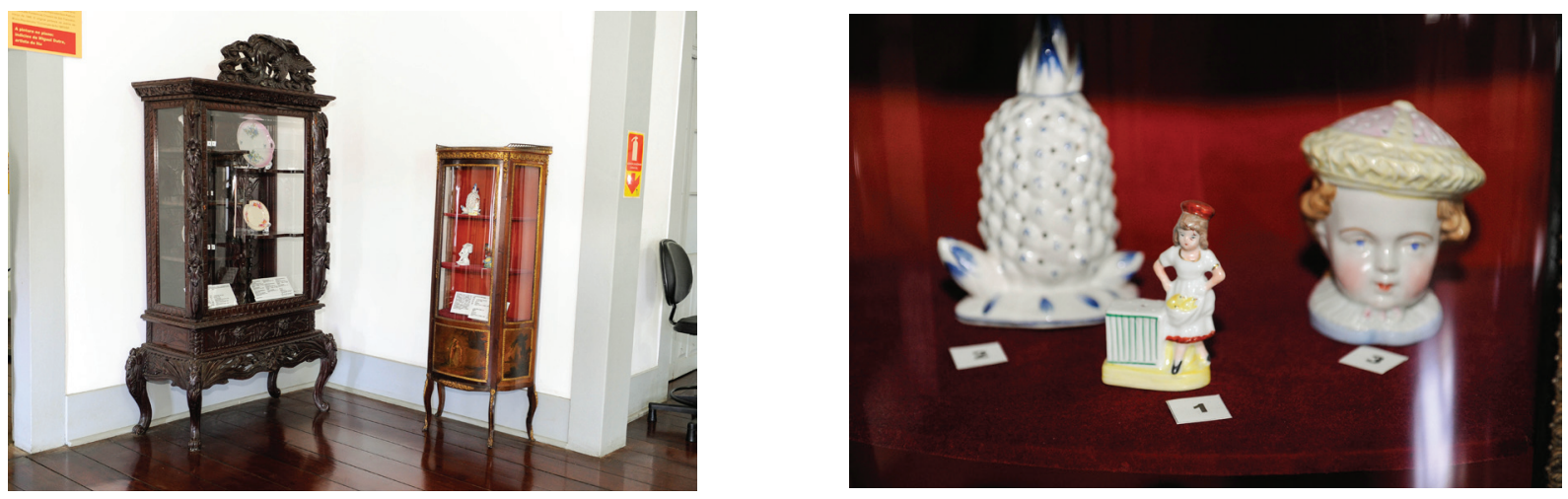

Figuras 21, 22: Vitrines de louça paulista e de paliteiros de porcelana. Fotografias de Marcos Steiner.

Ao lado dos menus e artefatos para processamento da alimentação, peças de mobiliário completam a exposição. Para além dos móveis do acervo do Museu Republicano que fazem as vezes de vitrines para a louça paulista e para os paliteiros, o conjunto de sala de jantar em exposição foi confeccionado na França, na década de 1860, encomendado para o casamento de José Francisco Monteiro (1830-1911) e D. Maria Belmira de França Monteiro. Cafeicultor, empresário e político, José Francisco Monteiro foi agraciado com o título de Barão de Tremembé, em 1868, e de Visconde de Tremembé, em 1887. É provável que tenha mobiliado a Chácara do Visconde, em Taubaté, onde seu neto, Monteiro Lobato, vivera até os 12 anos de idade. A chácara teria inspirado a criação do Sítio do Pica-Pau Amarelo e o avô, o Visconde de Sabugosa.

Os móveis sempre permaneceram com a família e passaram por várias gerações, chegando às mãos da sra. Joyce Campos Kornbluh (neta de Monteiro Lobato e tataraneta do Visconde de Tremembé), que, juntamente com sua filha, a sra. Cleo Campos Hill, ofereceu o conjunto em doação ao Museu Paulista, em 2014 (figura 23).

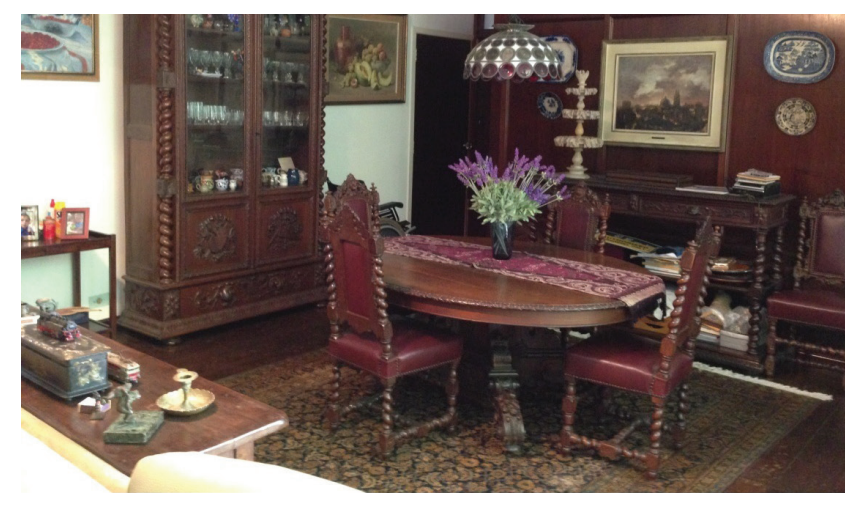

Figura 23: Sala de jantar na residência da sra. Joyce Campos Kornbluh.

Fotografia de Vânia Carneiro de Carvalho.

Em Cardápios e banquetes na Primeira República, tal conjunto compõe o gran finale do discurso museográfico (figuras 24, 25). Ornada com toalha dos anos 1930 e centro de mesa inglês em metal e cristal que pertencera ao ex-presidente Campos Salles, a mesa de jantar do Visconde de Tremembé 
e todos os móveis a ela relacionados passaram a assumir o papel que tinham móveis similares nas casas da elite da segunda metade do oitocentos e nas primeiras décadas do século XX, onde ocorriam os jantares e almoços festivos. Mas não só. As reuniões no espaço doméstico mimetizam os banquetes ocorridos no espaço público à medida que os jantares cerimoniosos se converteram em importante espaço para consolidação e criação de novas alianças econômicas e políticas, o que na exposição é sugerido pelas projeções nas paredes que circundam o conjunto de jantar de cenas dos banquetes da Coleção Washington Luís e recortes de imagens dos convivas, muitos dos quais, em espaço privado, certamente desempenhavam os papéis ora de anfitriões, ora de comensais.
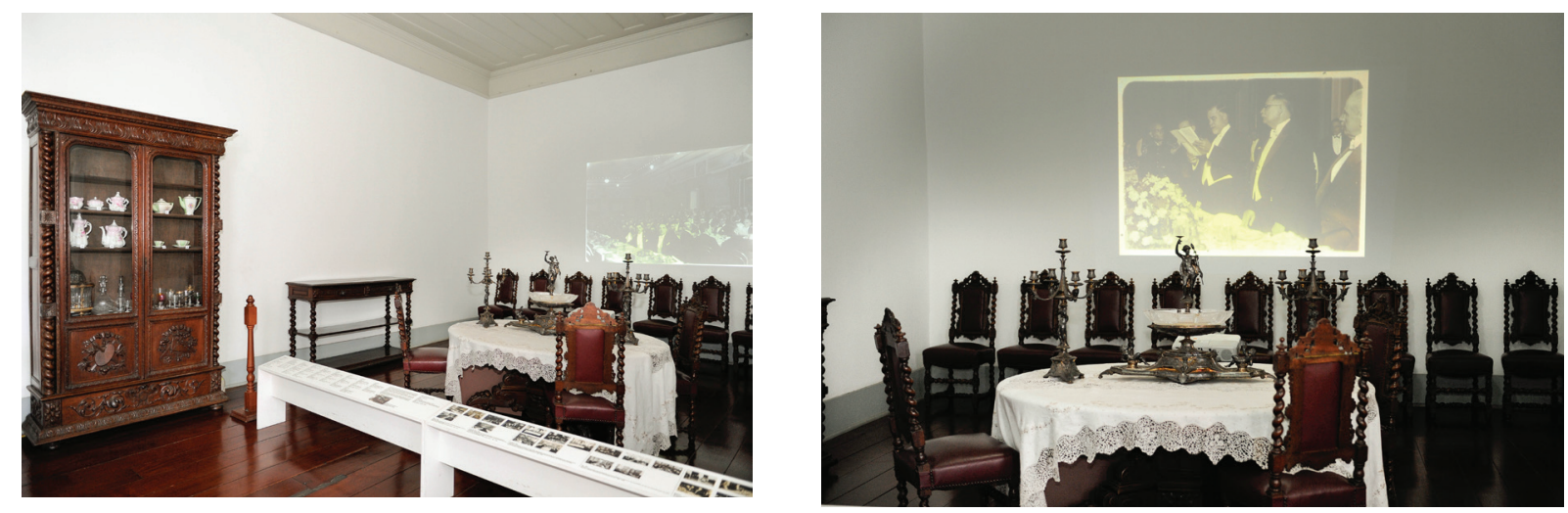

Figuras 24, 25: Vista parcial da exposição no Museu Republicano de Itu. Fotografias de José Rosael.

\section{Atividades de difusão em torno de práticas alimentares}

Como a exposição foi inaugurada em 10 de novembro, várias atividades acadêmicas e culturais em torno das práticas sociais e alimentares da Primeira República (1889-1930) foram planejadas para a Semana da República de 2015, que teve forte participação de vários segmentos da comunidade ituana. Os eventos contaram com parcerias bem sucedidas entre o Museu Republicano e instituições locais - Secretaria da Cultura e Secretaria de Turismo da Estância Turística de Itu, Museu da Música de Itu e fazendas da região.

No Centro de Estudos do Museu Republicano, localizado a poucos metros do museu, na mesma rua, foi aberta uma mostra temporária sobre Práticas alimentares na Primeira República que dialogava com a exposição Cardápios e banquetes, privilegiando a região de Itu. Os serviços de Arquivo Histórico e Fotografia, de Objetos e de Biblioteca9 ${ }^{9}$ selecionaram documentos de seus acervos, expondo outros cardápios e fotografias dos eventos; objetos utilizados para os serviços de mesa; material de periódicos locais sobre a temática.

Um ciclo de palestras sobre temas afeitos à alimentação e às práticas sociais no período em questão foi organizado no auditório do Centro de Estudos voltado aos alunos dos cursos de graduação em História, Gastronomia e Letras do Centro Universitário Nossa Senhora do Patrocínio (Ceunsp), mas aberto ao público interessado em geral, com transmissão pelo IPTV. A professora

9 Integram o Serviço de Arquivo Histórico e Fotografia Anicleide Zequini e Giovanna Balsan; o serviço de Objetos e Conservação, Rosana Aguilera e Marcos Steiner; o serviço de Biblioteca, José Renato Galvão e Alzira Nobre. 
Vânia Carneiro de Carvalho ministrou a palestra "O comer como ato social"; Eliane Morelli Abrahão discorreu sobre "Cardápios de banquetes: a estética dos sabores"; e Heloísa Maria Silveira Barbuy proferiu a comunicação "A louça dos barões: conformações, usos e reverberações".

Após as aulas, o público pôde provar quitutes de época preparados por Suely Quinzani Sani Pereira, com auxílio dos alunos do curso de gastronomia da Faculdade de Hospitalidade do Ceunsp, e doces e produtos tradicionais das fazendas da região de Itu - Capoava, Armazém do Limoeiro, Fazenda Concórdia e Fazenda e Camping das Pedras de Itu.

Idealizada pelo regente Luís Roberto de Francisco, a Soirée Musical Republicana contou com a participação de Vinícius Costa (piano), Fátima Oliveira e Amanda de Souza (sopranos) e revelou aspectos da música tocada e cantada pela elite paulista nos anos iniciais da República, sobretudo em saraus e encontros sociais.

Por fim, a semana se encerrou com jantar e seresta na Chácara do Rosário, casa bandeirista do século XVIII. No evento, organizado pelo proprietário João Pacheco, foram oferecidos pratos que fizeram parte do banquete servido ao Presidente Washington Luís em 20 de fevereiro de 1926, na inauguração do asilo Nossa Senhora da Candelária de Itu.

\section{Desdobramentos da curadoria museológica}

Em fevereiro de 2016, mês de aniversário da cidade, a mostra do Centro de Estudos deu lugar à exposição temporária $\mathrm{O}$ comércio de alimentos na Itu de antigamente, trazendo fotografias do acervo e reproduções de anúncios e matérias de jornais da cidade, guardados na biblioteca do Museu, desde fins do século XIX até a primeira metade do XX, sobre feiras, mercado municipal, matadouro, padarias, confeitarias, armazéns, restaurantes, hotéis. A inauguração foi precedida por uma mesa redonda que discutiu as práticas alimentares nas ruas de São Paulo e Itu na Primeira República, formada pelos professores João Máximo da Silva, Rafaela Basso e Maurício Lopes Maiolo.

As exposições sobre as práticas alimentares - Cardápios e banquetes na Primeira República e Comércio de a limentos na Itu de antigamente - fomentaram duas pesquisas acadêmicas.

A pesquisa de mestrado de Luís Fernando Conçalves Teberga, intitulada As transformações nas práticas alimentares paulistas (Itu, 1873-1889), se concentra na análise das dinâmicas relativas às práticas alimentares no município de Itu entre as décadas de 70-80 do século XIX a partir da análise dos anúncios relacionados ao tema encontrados nos periódicos produzidos na cidade à época. De forma mais específica, a pretensão é avaliar como a introdução de alimentos, comercializados em novos tipos de estabelecimentos, atuou sobre a ementa alimentar daquela sociedade praticada até meados do século XIX.

Já Eliane Morelli Abrahão desenvolve a pesquisa de pós-doutoramento A estética dos sabores e do poder: os cardápios da Coleção Washington Luís, que discute os banquetes ocorridos durante a Primeira República como espaços e instrumentos de poder que engendravam a teia política com desdobramentos no campo regional e nacional. Partindo da coleção Washington Luís - mas não restrita a ela -, analisa aspectos das práticas alimentares, colocando em perspectiva histórica as 
ações comportamentais de um segmento da sociedade - elites econômica, política e cultural-, que tornam visíveis a alimentação como uma linguagem de pertencimento social e no fortalecimento da imagem de unidade e modernidade do Estado. Entre os resultados esperados, estão previstas a confecção de material educativo para a exposição e a inserção de novos núcleos temáticos, em razão da ampliação da pesquisa junto a arquivos de São Paulo, Campinas e Rio de Janeiro.

Por fim, em 2018, foram implantados recursos multissensoriais na exposição Cardápios e banquetes, integrantes de um projeto maior que visa tornar o Museu Republicano de Itu mais acessível a diversos públicos que frequentam a instituição ${ }^{10}$. Tal projeto vem se desenvolvendo desde 2015 e tem contado com verbas da Pró-Reitoria de Cultura e Extensão da USP, na linha de projetos de fomento, do Santander/FUSP e do próprio Museu Paulista.

Para essa exposição em particular foram encomendadas réplica do busto de Prudente de Moraes em impressora 3D e impressões em braile para legendas e para o cardápio do banquete oferecido a Washington Luís na inauguração do Asilo Nossa Senhora da Candelária em 1926, na cidade de Itu. Tal como o busto, várias peças de louça que integravam o acervo do serviço educativo foram disponibilizadas como objetos táteis não só para visitantes com necessidades especiais - embora eles sejam o público-alvo -, mas a todos que queiram vivenciar a exposição de formas diferenciadas (figuras 26, 27).

Ainda que sempre possamos acrescentar novos recursos às exposições, certamente o passo inicial foi dado e o público em geral já pode se beneficiar de um museu gratuito, mais acessível e inclusivo.
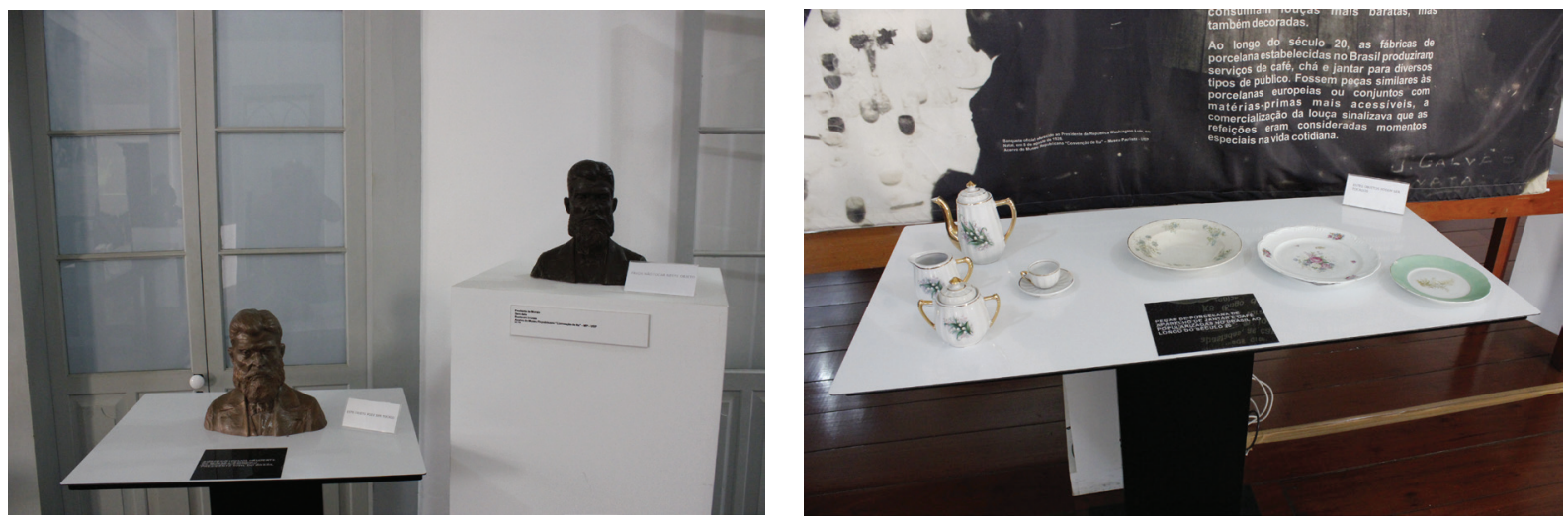

Figuras 26, 27: Recursos de acessibilidade na exposição. Fotografias de Marcos Steiner. 


\section{Referências}

ABRAHÃO, Eliane Morelli. Morar e viver na cidade. Campinas (1850-1900). Mobiliário e utensílios doméstico. São Paulo: Alameda/Fapesp, 2010. História da alimentação: cadernos de receitas e práticas alimentares Campinas (1860-1940). Campinas: Pontes Editores, 2018.

ALMEIDA, Julia Lopes de. O livro das noivas. São Paulo: Castorino Mendes, 1929.

BRAGA, Isabel M. R. Mendes Drumond. Os menus em Portugal. Para uma história das artes de servir à mesa. Lisboa: Chaves Ferreira Publicações, 2006.

BREFE, Ana Cláudia. Museu Paulista: Affonso de Taunay e a memória nacional 1917-1945. São Paulo: Editora Unesp/Museu Paulista, 2005.

CAMPORESI, Piero. Hedonismo e exotismo. A arte de viver na época das Luzes. São Paulo: Editora Unesp, 1996.

CARVALHO, Vânia Carneiro de. Cênero e artefato. O sistema doméstico na perspectiva da cultura material-São Paulo, 1870-1920. São Paulo: Edusp/Fapesp, 2008.

. Cultura material, espaço doméstico e musealização. Varia Historia, Belo Horizonte, v. 27, n. 46, pp. 443-469, jul/dez 2011.

CLESER, Vera. O lar doméstico. Conselhos para boa direção de uma casa. 3. ed. Rio de Janeiro: Laemmert \& C.; São Paulo: Livreiros Editores, 1906.

FLANDRIN, Jean-Louis. L'Ordre des Mets. Paris: Odile Jacob, 2002.

GARCIA, Lúcia. Para uma história da Belle Époque: os cardápios de Olavo Bilac. São Paulo: Imprensa Oficial do Estado de São Paulo; Rio de Janeiro: Academia Brasileira de Letras, 2011.

LAURIOUX, Bruno. A Idade Média à mesa. Lisboa: Publicações Europa-América, 1989.

LELLIS, Francisco; BOCCATO, André. Os banquetes do Imperador. São Paulo: Editora Senac São Paulo/ Boccato, 2013.

MENESES, Ulpiano Bezerra de. Do teatro da memória ao laboratório da História: a exposição museológica e o conhecimento histórico. Anais do Museu Paulista, São Paulo, n. sér., pp. 9-42, jan./dez. 1994.

PEREIRA, José Hermes. Louça paulista. As Primeiras Fábricas de Faiança e Porcelana no Estado de São Paulo. São Paulo: Imprensa Oficial/Museu Paulista, 2010.

PILLA, Maria Cecília Barreto Amorim. Gosto e deleite: construção e sentido de um menu elegante. História: Questões \& Debates, Curitiba, n. 42, pp. 53-69, 2005.

SOUZA, Jonas Soares de. De casa a museu: 80 anos do Museu Republicano "Convenção de Itu". Anais do Museu Paulista, São Paulo, n. 10/11, pp. 213-225, 2003. 